\title{
Prevalence of severe acute rotavirus gastroenteritis and intussusceptions in Ghanaian children under 5 years of age
}

\author{
Christabel C. Enweronu-Laryea ${ }^{1}$, Kwamena W. C. Sagoe ${ }^{2}$, Hope Glover-Addy ${ }^{3}$, Richard H. \\ Asmah $^{4}$, Julius A. Mingle ${ }^{2}$, George E. Armah ${ }^{5}$ \\ ${ }^{1}$ Department of Child Health, University of Ghana Medical School, Accra, Ghana \\ ${ }^{2}$ Department of Microbiology, University of Ghana Medical School, Accra, Ghana \\ ${ }^{3}$ Department of Surgery, Korle Bu Teaching Hospital, Accra, Ghana \\ ${ }^{4}$ School of Allied Health Sciences, University of Ghana, Legon, Ghana \\ ${ }^{5}$ Noguchi Memorial Institute for Medical Research, University of Ghana, Legon, Ghana
}

\begin{abstract}
Introduction: Vaccination is the most effective preventive strategy against rotavirus disease. Regional differences in prevalent rotavirus genotypes may affect vaccine efficacy. Pre-vaccine surveillance for burden of rotavirus disease, prevalent rotavirus genotypes, and association between rotavirus disease and intussusceptions helps in monitoring the impact of vaccination.

Methodology: A prospective study was conducted from January 2008 to December 2009 in children younger than five years hospitalized for longer than 24 hours with acute gastroenteritis. Data on confirmed cases of intussusception were collected retrospectively. Stools were tested by enzyme immunoassay, reverse-transcriptase polymerase chain reaction and nucleotide sequencing.

Results: Acute gastroenteritis (AGE) caused $13.1 \%(2,147 / 16,348)$ of hospitalizations among children under five years. Stools were tested for $50.2 \%$ (1077/2147) of AGE cases. Of these, 49\% (528/1077) were rotavirus positive. Rotavirus gastroenteritis, non-rotavirus gastroenteritis, and intussusceptions were most prevalent in children under 15 months [80.3\%, 74\% and 91\% respectively]. Rotavirus was detected from more than $60 \%$ of acute gastroenteritis cases during peak months. The prevalence of intussusception showed no seasonal pattern. The peak ages of six to twelve months for acute gastroenteritis and five to eight months for intussusception overlapped. G1, G2 and mixed G/P genotypes were common in the isolated rotaviruses.

Conclusion: Rotavirus gastroenteritis causes significant morbidity in children younger than five years of age in Ghana. Although the peak age of rotavirus gastroenteritis and intussusceptions overlapped, there was no seasonal correlation between them. The high prevalence of mixed G/P genotypes in Ghanaian children may affect the effectiveness of vaccination.
\end{abstract}

Key words: rotavirus; gastroenteritis; intussusceptions; genotype; vaccination

J Infect Dev Ctries 2012; 6(2):148-155.

(Received 18 October 2010 - Accepted 14 June 2011)

Copyright (c) 2012 Enweronu-Laryea et al. This is an open-access article distributed under the Creative Commons Attribution License, which permits unrestricted use, distribution, and reproduction in any medium, provided the original work is properly cited

\section{Introduction}

Rotavirus is the most common cause of acute gastroenteritis (AGE) in children younger than five years of age worldwide. Each year two million children younger than five years are hospitalized with rotavirus AGE and an estimated 527,000 children die. The majority of these deaths occur in developing countries [1,2]. Rotavirus causes about $30-50 \%$ of diarrheal diseases in young children and the prevalence of severe rotavirus disease has remained high [3,4] despite improvements in sanitation. An explanation for this may be that improved hygienic practices and oral rehydration therapy have resulted in a greater decline of hospitalization from bacterial and parasitic diarrheal diseases than hospitalization from rotavirus disease [5,6]. Vaccination is considered the most effective public health strategy to reduce rotavirus disease burden [7].

Intussusception, a known cause of acute intestinal obstruction in children younger than five5 years of age, is potentially lethal. The etiology of intussusception is poorly understood. There has been no convincing evidence to date that it is caused by rotaviruses but its temporal association with the first licensed rotavirus vaccine RotaShield, led to the withdrawal of the vaccine in 1999 [8]. Two new rotavirus vaccines have recently been licensed and epidemiological studies have not shown any causal 
association of these vaccines with intussusceptions $[9,10]$.

The licensed vaccines which contain high levels of the most common globally prevailing rotavirus genotype G1P8 have been shown to be very effective in reducing the burden of severe rotavirus disease in Europe, the United States, and Latin America [11]. These vaccines have shown varying levels of effectiveness in Africa [12]. The differences may be due to variations in rotavirus genotypes among regions. Geographic differences in the diversity of strains and changes in infecting strains over time in the same geographical area have been described $[13,14]$. Pre-vaccine and post-vaccine introduction surveillance for circulating rotavirus strains will be useful for monitoring rotavirus disease patterns and the impact of vaccination.

Rotavirus vaccine has not yet been introduced into the private and public health service in Ghana. The World Health Organization (WHO) recommends that countries conduct local surveillance studies prior to the introduction of new vaccines $[3,15]$. We report on the prevalence of severe rotavirus AGE, common rotavirus genotypes, and intussusceptions in Ghanaian children younger than five years old. Surveillance for burden of rotavirus disease, prevalent rotavirus genotypes, and association between rotavirus disease and intussusception before introduction of vaccination will help in monitoring its impact.

\section{Methodology}

Study design

We conducted a prospective multicentre study in a convenience sample of three hospitals within a 10kilometer radius in Accra Metropolis, Ghana's capital city, from January 2008 to December 2009. The population of Accra is estimated to be about four million and these three hospitals provide inpatient care to over $50 \%$ of hospitalized children in the city. Two of the chosen hospitals, Children's Hospital $(\mathrm{CH})$ and District Hospital (DH), provide both primary and secondary levels of care. The third hospital, Korle Bu Teaching hospital (KBTH), provides tertiary medical care and pediatric surgery services for $\mathrm{DH}$ and $\mathrm{CH}$, and many other hospitals in the southern regions of Ghana.

\section{Study population}

Children younger than five years of age who were hospitalized for longer than 24 hours by a medical officer with a primary diagnosis of AGE (defined as $\geq 3$ watery stools voided within 24 hours for $\leq 7$ days) at any of the three hospitals met the inclusion criteria for the study. Children with bloody stools or those whose parents did not give consent were excluded. Sampling strategy consisted of continuous daily enrollment throughout the year at DH hospital, and only daytime enrollment (except weekends and statutory holidays) at $\mathrm{CH}$ and KBTH. Participation in the study was voluntary and no incentive was given to encourage participation.

\section{Data collection and laboratory analysis}

A standard questionnaire was used to collect demographic (date of birth, age, gender, date of hospitalization and discharge) and clinical (episodes of diarrhea, vomiting, fever, treatment given, outcome) data from the parents and hospital folders. Data on children younger than five years with confirmed discharge diagnosis (by ultrasonography or at surgery) of intussusception during the study period was collected retrospectively from the pediatric surgical unit register. Data on all pediatric medical hospitalizations of children younger than five years were collected from the admissions and discharges registers of the participating hospitals.

Stool samples were collected in a labeled screwtop container no later than seven days after the onset of the illness and stored at $4^{\circ} \mathrm{C}$ until they were tested by rotavirus enzyme immuno-assay (IDEIA kit, DAKO Diagnostics, Cambridgeshire, United Kingdom) for detection of rotavirus antigen. Rotavirus-positive specimens were sent to the Noguchi Memorial Institute of Medical Research reference virology laboratory for determination of rotavirus genotype by a reverse-transcriptase polymerase chain reaction (RT-PCR) method and nucleotide sequencing [16]. Quality control was ensured by re-testing $10 \%$ of EIA-negative stool specimens at the reference laboratory.

\section{Data analysis}

All data were entered into a database using the Epi Info 3.5.1 (CDC, Atlanta, Georgia, USA) and analyzed with Stata version 10 (StataCorp, College Station, TX, USA). The proportion of AGE cases among all hospitalized children younger than five years was calculated for each center and overall, using as a denominator the total number of children less than five years old hospitalized during the study period. The proportions of rotavirus gastroenteritis among AGE hospitalizations in children younger than five years of age and all hospitalized children 
Table 1. Prevalence of severe acute rotavirus gastroenteritis in children younger than 5 years old at 3 levels of health-care delivery in participating hospitals

\begin{tabular}{|c|c|c|c|c|c|}
\hline & \multicolumn{2}{|c|}{ Hospitalizations } & \multicolumn{2}{|c|}{$\begin{array}{c}\begin{array}{c}\text { Prevalence of rotavirus } \\
\text { gastroenteritis }\end{array} \\
\end{array}$} & \multirow{2}{*}{$\begin{array}{c}\text { Rotavirus } \\
\text { gastroenteritis } \\
\text { hospitalizations } \\
(\%)\end{array}$} \\
\hline & $<5$ years & $\begin{array}{l}\text { AGE* } \\
\text { cases }\end{array}$ & $\begin{array}{l}\text { No. Stools } \\
\text { tested }\end{array}$ & $\begin{array}{l}\text { Rotavirus } \\
\text { positive }(\%)\end{array}$ & \\
\hline Primary level care & 2040 & $242 \quad(11.9)$ & 246 & $105 \quad(42.7)$ & 5.1 \\
\hline Secondary level care & 6182 & $(18.1)$ & 386 & $(50.2)$ & 9.1 \\
\hline Tertiary care & 8126 & $(9.7)$ & 445 & $(51.5)$ & 5.0 \\
\hline Total & 16348 & $(13.1)$ & 1077 & (49) & 6.4 \\
\hline
\end{tabular}

younger than five years were computed. Proportions were compared by $\chi 2$-tests, odds ratio (OR), and $95 \%$ confidence interval (95\% CIs).

\section{Results}

During the 2 years of the study, 16,348 children younger than five years were hospitalized, and $13.1 \%$ (2147) of these cases were due to AGE. None of the children whose stools were collected for the study was admitted more than once for AGE. We collected demographic and clinical data and stool specimens from 1,080 of the 2,147 AGE hospitalizations. Three stool specimens were insufficient; thus $50.2 \%$ (1077/2147) of the stool specimens were tested. Of the AGE cases tested, $49 \%$ were rotavirus positive; thus $6.4 \%$ of all hospitalizations of children younger than five years could be attributed to rotavirus disease. There was no significant observed difference between the prevalence of rotavirus disease among AGE cases for whom stool testing was done in 2008 vs. $2009\{239 / 519(46.1 \%)$ versus $289 / 558(51.8 \%)$ OR $1.27(95 \%$ CI $1.0-1.6) p=0.51\}$. Hospitalization for rotavirus disease was highest at $\mathrm{CH}$, a children's hospital. The distribution of hospitalizations and AGE cases at the participating hospitals is shown in Table 1.

\section{Seasonal distribution}

The proportion of AGE cases whose stools were collected for analysis during the study was greater than $90 \%$ at $\mathrm{DH}, 45 \%$ to $52 \%$ at $\mathrm{CH}$, and $50 \%$ to $60 \%$ at KBTH for all other months except the months of December for both years of the study when smaller percentages of stool specimens (30\% to 35\%) were collected for AGE cases. The monthly proportion of all hospitalizations of children younger than five years due to AGE varied from $3 \%$ to $37 \%$. Rotavirus was isolated from the stools of more than $30 \%$ of all children hospitalized with AGE throughout the year and from more than $60 \%$ of stools during the peak months. The peak months occurred during the dry season in 2008 and the rainy season in 2009. The seasonal pattern of rotavirus and non-rotavirus AGE during both years are shown in Figure 1.

\section{Age distribution}

We found that $73 \%$ of all children younger than five years hospitalized for AGE were less than 15 months old. Among those whose stools were tested, $74 \%(406 / 549)$ of non-rotavirus AGE and $80.3 \%$ (424/528) of rotavirus AGE cases occurred in children younger than 15 months. Rotavirus AGE occurred less frequently than non-rotavirus AGE in children less than three months old [32/528 versus 59/549 OR 0.54 (95\% CI $0.34-0.84) p=0.006]$. The peak age for AGE of any cause was 6 to 12 months. Figure 2 shows the age distribution of AGE by cause and for intussusceptions.

\section{Clinical features and outcome}

There was no significant difference in the severity of diarrhea and fever among children with rotavirus and non-rotavirus AGE as shown in Table 2. Severe vomiting and consequent use of intravenous fluid rehydration occurred more frequently in children with rotavirus AGE ( $\mathrm{p}<$ 0.001). Non-rotavirus AGE was associated with worse morbidity as shown by the significantly longer duration of hospitalization. Thirteen children admitted with AGE died during the two years of the study, and three $(23 \%)$ of these deaths occurred in rotavirus-positive cases. Even though a greater proportion of children with non-rotavirus AGE died compared to those with rotavirus AGE, the difference in proportions of deaths within these AGE categories was not statistically significant $(\mathrm{p}=0.09)$. 
Figure 1.

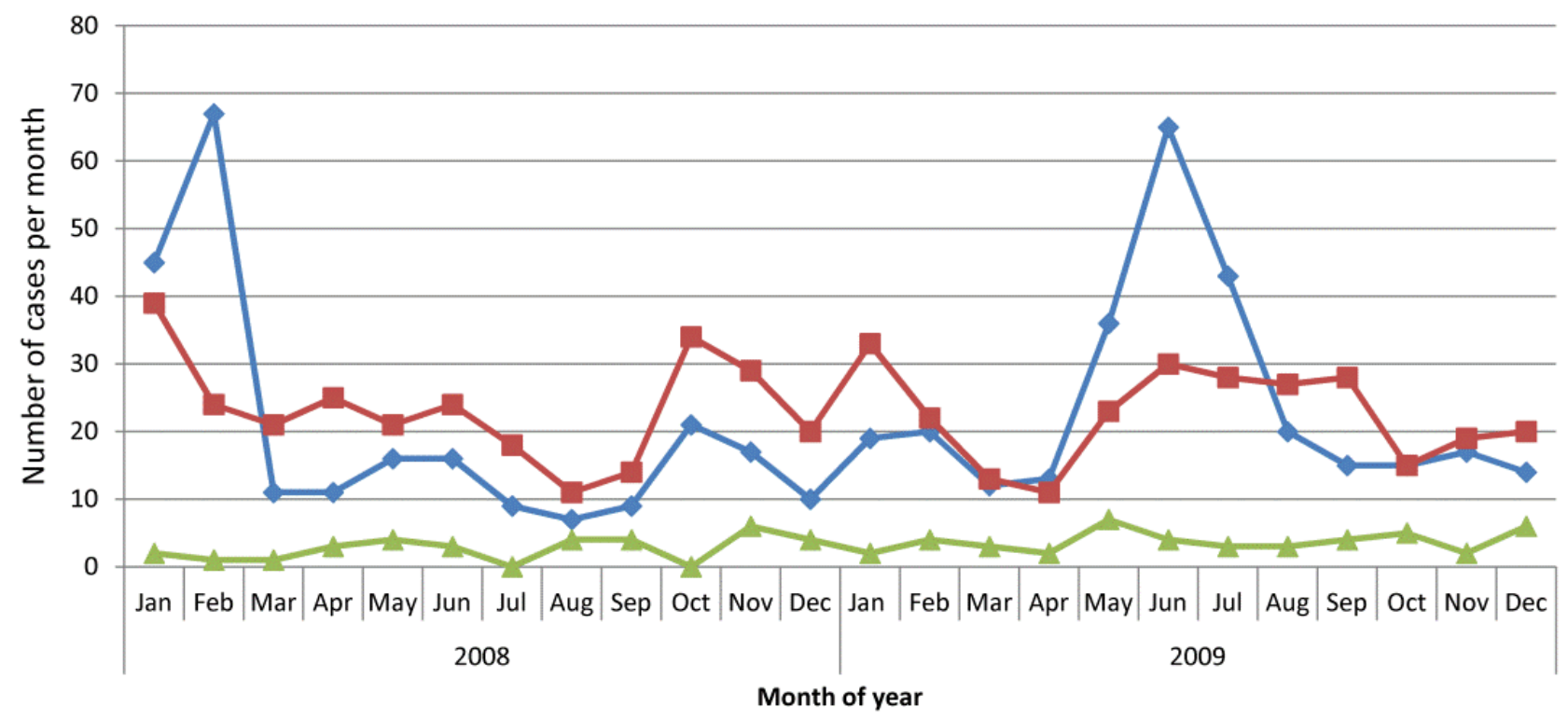

$\neg$ Rotavirus positive $(n=528) \quad-$ Rotavirus negative $(n=549) \quad-$ Intussusception $(n=77)$

Figure 2.

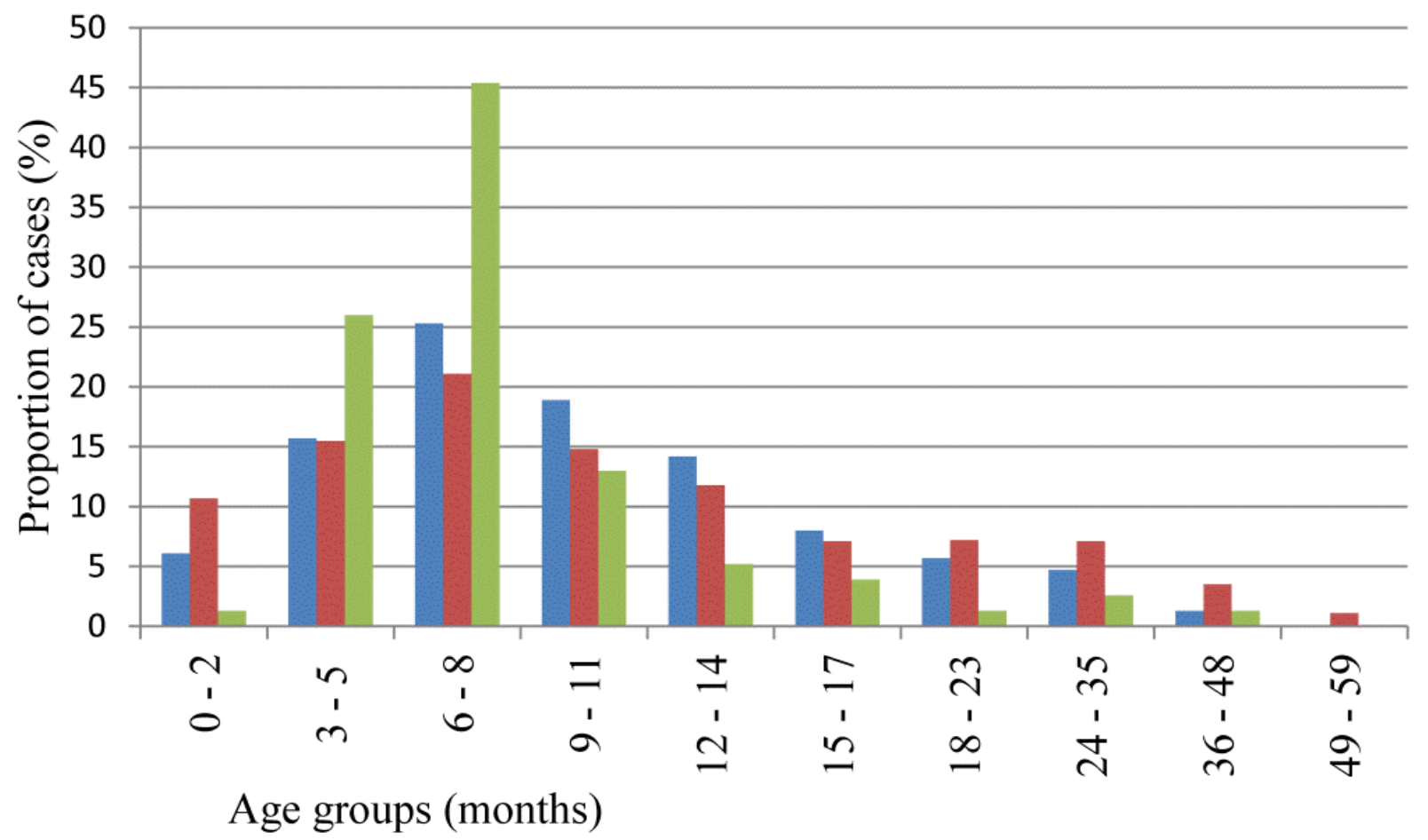

Rotavirus positive (528) $\quad$ Rotavirus negative (549) Intussusception(77) 
Table 2. Clinical features of rotavirus and non-rotavirus severe acute gastroenteritis in children younger than 5 years old

\begin{tabular}{|l|c|c|l|l|}
\hline & $\begin{array}{c}\text { Rotavirus gastroenteritis } \\
\mathrm{n}=528(\%)\end{array}$ & $\begin{array}{c}\text { Non-rotavirus gastroenteritis } \\
\mathrm{n}=549(\%)\end{array}$ & \multicolumn{1}{|c|}{$\begin{array}{l}\text { OR } \\
(95 \% \mathrm{CI})\end{array}$} & $p$ value \\
\hline $\begin{array}{l}\text { Episodes of diarrhea } \\
>10 / \text { day }\end{array}$ & $121(22.9)$ & $117(21.3)$ & $\begin{array}{l}1.1(0.82- \\
1.45)\end{array}$ & 0.57 \\
\hline $\begin{array}{l}\text { Episodes of vomiting } \\
>10 / \text { day }\end{array}$ & $113(21.4)$ & $65(11.8)$ & $\begin{array}{l}2.0(1.44- \\
2.86)\end{array}$ & $<0.001$ \\
\hline $\begin{array}{l}\text { High grade fever } \\
>38.5^{\circ} \mathrm{C}\end{array}$ & $81(15.3)$ & $92(16.7)$ & $\begin{array}{l}0.9(0.65- \\
1.25)\end{array}$ & 0.56 \\
\hline $\begin{array}{l}\text { Hospitalization } \\
\geq 7 \text { days }\end{array}$ & $74(14)$ & $124(22.6)$ & $\begin{array}{l}0.56(0.40- \\
0.77)\end{array}$ & $<0.001$ \\
\hline Mortality & $3(0.6)$ & $10(1.8)$ & $\begin{array}{l}0.3(0.09- \\
1.04)\end{array}$ & 0.09 \\
\hline
\end{tabular}

\section{Intussusceptions}

There were 77 cases of confirmed intussusceptions in children less than five years old during the two years of the study. There was no association between the seasonal pattern of AGE of any cause and intussusceptions. The majority (91\%; 70/77) of intussusception cases occurred in children younger than 15 months (peak age five to eight months). The seasonality and age distribution of AGE and intussusceptions are shown in Figures 1 and 2 respectively.

\section{Rotavirus strains}

We tested $94.9 \%(501 / 528)$ of the EIA positive stools for identification of rotavirus genotype. The most common genotypes, G1 and G2, represented $61 \%(307 / 501)$ of all strains. G4 and G8 were the most uncommon strains as shown in Table 3. Of the mixed G types, G1G2 (30\%; 11/38), G1G3 (21\%; $8 / 38)$ and G1G8 (13.2\%; 5/38) were the most common. G12 was isolated in two children as G12G10 and G12G3 mix. Of the P serotypes, P[6] was the most common during both years of the study and represented $34.5 \%(173 / 501)$, followed by $\mathrm{P}[8]$ (19.8\%; 99/501), P[4] (9.4\%; 47/501), mixed P types $(26.5 \% ; 135 / 501)$ and nontypeable $\mathrm{P}$ types $(9.4 \%$; 47/501). P[6,8] mix $(34.8 \% ; 47 / 135)$ was the most common combination. About one third of $(32.3 \%)$ children were infected with mixed G/P genotypes. Of the non-mixed rotavirus strains, infections with G1P[8] (14.8\%; 74/501) were the most common.

\section{Discussion}

This study illustrates the substantial burden of AGE in Ghanaian children younger than five years of age, especially those less than 15 months old.
Rotavirus disease accounted for one out of $15(6.4 \%)$ of all hospitalized children under five years of age and one out of two (49\%) children hospitalized for AGE in those studied. The incidence of $42 \%$ to $51.5 \%$ at the three levels of health care in our study is comparable to the data from inpatient studies from developed countries [17,18], but higher than the numbers reported from other African countries [19]. The differences may be due to the varied inclusion criteria used in the African studies. The higher prevalence in our study could be explained by the restriction of duration of illness to $\leq 7$ days in our inclusion criteria; many studies in Africa enroll children up to 14 days after the onset of illness. Rotavirus shedding in children with AGE occurs maximally in the first week of the illness [20].

The children most affected by rotavirus and nonrotavirus AGE in our study were 3 to 14 months old and the peak age for rotavirus AGE was 6 to 12 months. The peak age occurs in older children in developed countries and elsewhere [18,21]. Ongoing surveillance in other African countries shows that children between the ages of three and 18 months have the highest incidence. The higher prevalence in younger African children may be explained by breastfeeding practices and unhygienic living conditions. Most infants in Ghana breastfeed but many do not breastfeed exclusively after the age of three to four months. Though there has been some improvement in hygienic practices in Ghana, inadequate water supply and poor sanitation facilities are still commonplace. These factors predispose many Ghanaian infants to feco-orally transmitted gastrointestinal infections because their immune system is too immature to handle the viral and 
Table 3. Rotavirus genotypes detected from rotavirus positive stool specimens

\begin{tabular}{|c|c|c|c|c|c|c|c|c|c|c|}
\hline & G1 & G2 & G3 & G4 & G8 & G9 & G10 & G mix & G uncharacterized & Total \\
\hline Year 2008 & 86 & 68 & 23 & 10 & 1 & 13 & 5 & 22 & 17 & 245 \\
\hline Year 2009 & 123 & 30 & 21 & 0 & 0 & 6 & 20 & 16 & 40 & 256 \\
\hline Total (\%) & 209 & 98 & 44 & 10 & 1 & 19 & 25 & 38 & 57 & 501 \\
$(41.7)$ & $(19.5)$ & $(8.8)$ & $(2)$ & $(0.2)$ & $(3.8)$ & $(5)$ & $(7.6)$ & $(11.4)$ & $(100)$ \\
\hline
\end{tabular}

bacterial load from water and complementary food sources [22].

Rotavirus disease occurred in more than $30 \%$ of AGE hospitalizations throughout the year. The peak incidence occurred in the dry season in 2008 and the rainy season in 2009. Distinct seasonal patterns of peak rotavirus incidence during dry cool months have been described in northern Ghana [23], Kenya [24] and during the winter months in temperate regions. Reports from Bangladesh have also described peaks during cool dry months in some parts of the country and two seasonal peaks of dry cool months and the monsoon season [25] as shown in this study. Other investigators have shown that seasonality is less marked in tropical countries [26].

Rotavirus disease accounted for $23 \%$ of AGE related deaths in this study. Similar proportions have been described worldwide [27]. Studies in northern Ghana [28], a rural area, estimated that $34 \%$ of AGE deaths were due to rotavirus. This higher rate of mortality as compared to our study may be attributed to the quality of health-care services available in rural settings. Many of these children required intravenous fluid therapy because of severe vomiting and the expertise and resources for caring for such children may not always be available in health-care centers in rural areas. More work on the burden of other nonrotavirus pathogens that commonly cause AGE in young Ghanaian children is needed to formulate a comprehensive approach to reduce the morbidity and mortality caused by diarrheal diseases.

The peak age of rotavirus AGE and intussusceptions overlap but there was no correlation in the seasonal pattern of the two conditions. This finding is similar to those of other studies [29,30]. It is unlikely that there is any association between these conditions but the overlap in age distribution may have implications for policy decisions on the age range for rotavirus immunization in Ghanaian children, even though newer rotavirus vaccines have not been associated with intussusceptions.
We found that genotypes G1 and G2 were common as described globally. While other investigators found G8 to be as common as G3 and G4 in Africa [19,31], our work did not confirm this. There were six G8 strains isolated during the two years of the study, and five of these were G1G8 mix. The high prevalence of $\mathrm{P}[6]$ in our work is similar to observations of other studies from Africa. High incidence of mixed infections has been reported from India [32]. These mixed infections may represent naturally occurring re-assortment among rotavirus [33]. It could also be due to rotavirus strains being present at different concentrations thus resulting in an uneven degree of PCR amplification that makes the interpretation of the gel band pattern difficult $[34,35]$.

Our study has some limitations. We collected data from public hospitals in an urban population. The burden of disease and rotavirus genotype may be different in private hospitals where high-income Ghanaian families usually seek medical care and in rural settings with inadequate health facilities. Irrespective of these limitations, we consider our data representative of the burden of rotavirus disease in Ghana because the majority of Ghanaians seek medical care in public health facilities. The poor collection of data in the month of December of each year (mostly due to statutory holidays) of the study limits any inferences we made about seasonal variations. It was difficult to accurately document Vesikari's scores in this study and therefore it was also difficult to compare the severity of illness in our work with that of other studies.

The substantial health burden of rotavirus disease in Ghanaian children underscores the need for effective interventions for control of rotavirus disease as part of a comprehensive approach for prevention and control of diarrheal diseases. Rotavirus vaccination has been shown to be effective in reducing hospitalization due to AGE of children younger than five years. We recommend the inclusion of rotavirus vaccination in the national 
expanded program of immunization in Ghana as an important step for reducing the burden of AGE in children less than five years old. Other interventions that promote breastfeeding and hygienic practices as well as improve water sources and sewage disposal should also be intensified. This study provides a valuable baseline to assess the future impact of vaccination and a platform for future epidemiologic studies of vaccine performance and rotavirus disease in Ghana.

\section{Acknowledgements}

We are grateful to Juanita Adams for her diligent work in specimen collection and data entry; Anna Aba Hayford, Belinda Lartey and Francis Dennis for laboratory services; and WHO Afro for sponsoring this project. The authors also appreciate support received from the African Rotavirus Surveillance Network and the World Health Organization.

\section{References}

1. Prashar UD, Hummelman EG, Bresse JS, Miller MA, Glass RI (2003) Global illness and deaths caused by rotavirus diseases in children. Emerg Infect Dis 9: 565-572.

2. World Health Organization. Estimated rotavirus deaths for children under 5 years of age, 2004. http://www.who.int/immunization_monitoring/burden/rotavi rus_estimates/en/. Last accessed March 2006.

3. Mwenda JM, Ntoto KM, Abebe A, Enweronu-Laryea C, Amina I, Mchomvu J, Kisakye A, Mpabalwani EM, Pazvakavambwa I, Armah GE, Seheri LM, Kiulia NM, Page $\mathrm{N}$, Widdowson MA, Steele AD (2010) Burden and epidemiology of rotavirus diarrhea in selected African countries: preliminary results from the African Rotavirus Surveillance Network. J Infect Dis 202 Suppl: S5-S11.

4. Bernstein DI (2009) Rotavirus overview. Pediatr Infect Dis J 28(3Suppl):S50-3

5. Parashar UD, Gibson CJ, Bresee JS, Glass GI (2006) Rotavirus and Severe Childhood Diarrhoea. Emerg infect Dis 12: 304-306.

6. Villa S, Guiscafre H, Martinez H, Munoz O, Guiterrez G (1999) Seasonal diarrheal mortality among Mexican Children. Bull World Health Org 77: 375-80.

7. Glass RI, Parashar UD, Bresee JS, Turcios R, Fischer TK, Widdowson MA Jiang B, Gentsch JR (2006) Rotavirus vaccines: current prospects and future challenges. Lancet 368: 323-332.

8. Centers for Disease Control Prevention (1999) Withdrawal of rotavirus vaccine recommendation. MMWR 48: 1007.

9. Vesikari T, Matson DO, Dennehy P, Van Damme P, Santosham M, Rodriguez Z, Dallas MJ, Heyse JF, Goveia MG, Black SB, Shinefield HR, Christie CD, Ylitalo S, Itzler RF, Coia ML, Onorato MT, Adeyi BA, Marshall GS, Gothefors L, Campens D, Karvonen A, Watt JP, O'Brien KL, DiNubile MJ, Clark HF, Boslego JW, Offit PA, Heaton PM; Rotavirus Efficacy and Safety Trial (REST) Study Team (2006) Safety and efficacy of a pentavalent humanbovine (WC3) reassortant rotavirus vaccine. N Engl J Med 354: 23-33.

10. Ruiz-Palacios GM, Perez-Schael I, Velazquez FR, Abate H, Breuer T, Clemens SC, Cheuvart B, Espinoza F, Gillard P, Innis BL, Cervantes Y, Linhares AC, López P, Macías-Parra
M, Ortega-Barría E, Richardson V, Rivera-Medina DM, Rivera L, Salinas B, Pavía-Ruz N, Salmerón J, Rüttimann R, Tinoco JC, Rubio P, Nuñez E, Guerrero ML, Yarzábal JP, Damaso S, Tornieporth N, Sáez-Llorens X, Vergara RF, Vesikari T, Bouckenooghe A, Clemens R, De Vos B, O'Ryan M; Human Rotavirus Vaccine Study Group (2006) Safety and efficacy of an attenuated vaccine against severe rotavirus gastroenteritis. N Engl J Med 354: 11-22.

11. Munos MK, Fischer Walker CL and Black RE (2010) The effect of rotavirus vaccine on diarrhoea mortality. Int $\mathbf{J}$ Epidemiol 39 (suppl1): i56-i62.

12. Armah GE, Sow SO, Breiman RF, Dallas MJ, Tapia MD, Feikin DR, Binka FN, Steele AD, Laserson KF, Ansah NA, Levine MM, Lewis K, Coia ML, Attah-Poku M, Ojwando J, Rivers SB, Victor JC, Nyambane G, Hodgson A, Schödel F, Ciarlet M, Neuzil KM (2010) Efficacy of pentavalent rotavirus vaccine against severe rotavirus gastroenteritis in infants in developing countries in sub-Saharan Africa: a randomized, double-blind, placebo-controlled trial. Lancet 376: 606-614.

13. Armah GE, Steele AD, Binka FN, Esona MD, Asmah RH, Anto F, Brown D, Green J, Cutts F, Hall A (2003) Changing Patterns of Rotavirus Genotypes in Ghana: Emergence of Human Rotavirus G9 as a Major Cause of Diarrhea in Children. J Clin Microbiol 41: 2317-2322. doi: 10.1128/JCM.41.6.2317-2322.2003

14. Steele AD, Ivanoff $\mathrm{B}$, and the African Rotavirus Network (2003) Rotavirus strains circulating in Africa during 19961999: emergence of G9 strains and P[6] strains. Vaccine 21: 361-367.

15. World Health Organization (2002) Generic protocols (i) hospital-based surveillance to estimate the burden of rotavirus gastroenteritis in children and (ii) a community based survey on utilization of health-care services for gastroenteritis in children. Geneva: World Health Organization.

http://www.rotavirusvaccine.org/documents/Generic_protoc ol_for_surveillance_WHO.pdf. Last accessed 9 February 2012.

16. Gentsch JR, Glass RI, Woods P, Gouvea V, Gorziglia M, Flores J, Das BK, Bhan MK (1992) Identification of group A rotavirus gene 4 types by polymerase chain reaction. $J$ Clin Microbiol 30: 1365-1373.

17. Payne DC, Staat MA, Edwards KM, Szilagyi PG, Gentsch JR, Stockman LJ, Curns AT, Griffin M, Weinberg GA, Hall CB, Fairbrother G, Alexander J, Parashar UD (2008) Active, population-based surveillance for severe rotavirus gastroenteritis in children in the United States. Pediatr 122: 1235-1243.

18. Forster J, Guarino A, Parez N, Moraga F, Román E, Mory O, Tozzi AE, de Aguileta AL, Wahn U, Graham C, Berner R, Ninan T, Barberousse C, Meyer N, Soriano-Gabarró M; and the Rotavirus Study Group (2009) Hospital-Based Surveillance to Estimate the Burden of Rotavirus Gastroenteritis among European Children. Pediatr 123: e393-e400.

19. Waggie Z, Hawkridge A, Hussey G (2008) Literature review of rotavirus prevalence in Africa. Pediatr 121 (Suppl): S131S132.

20. Parashar UD, Bresee JS, Gentsch JR, and Glass RI (1998) Rotavirus. Emerg Infect Dis 4: 561-570.

21. Nguyen TV, Le Van P, Le Huy C, Weintraub A (2004) Diarrhea caused by rotavirus in children less than 5 years of age in Hanoi, Vietnam. J Clin Microbiol 42: 5745-5750. 
22. Plenge-Bonig A, Soto-Ramirez N, Karmaus W, Petersen G, Davis S, Forster J (2010) Breastfeeding protects against acute gastroenteritis due to rotavirus in infants. Eur J Pediatr 169: 1471-1476.

23. Armah GE, Mingle JA, Dodoo AK, Anyanful A, Antwi R, Commey J, Nkrumah FK (1994) Seasonality of rotavirus infection in Ghana. Ann Trop Paediatr 14: 223-229.

24. Kiulia NM, Kamenwa R, Irimu G, Nyangao JO, Gatheru Z, Nyachieo A, Steele AD, Mwenda JM (2008) The epidemiology of human rotavirus associated with diarrhoea in Kenyan children: a review. Trop Paediatr 54: 401-405.

25. Rahman M, Sultana R, Ahmed G, Nahar S, Hassan ZM, Saiada F, Podder G, Faruque AS, Siddique AK, Sack DA, Matthijnssens J, Van Ranst M, Azim T (2007) Prevalence of G2P[4] and G12P[6] Rotavirus, Bangladesh. Emerg Infect Dis 13: $18-24$.

26. Cook SM, Glass RI, LeBaron CW, Ho MS (1990) Global seasonality of rotavirus infections. Bull World Health Organ 68: 171-177.

27. Parashar UD, Burton A, Lanata C, Boschi-Pinto C, Shibuya K, Steele D, Birmingham M, Glass RI (2009) Global mortality associated with rotavirus disease among children in 2004. J Infect Dis 200 (Suppl 1): S9-S15.

28. Arvay ML, Curns AT, Terp S, Armah G, Wontuo P, Parashar UD, Binka F, Glass RI, Widdowson MA(2009) How much could rotavirus vaccines reduce diarrheaassociated mortality in northern Ghana? A model to assess impact. J Infect Dis 200 (Suppl 1): S85-91.

29. Chouikha A, Fodha I, Maazoun K, Ben Brahim M, Hidouri S, Nouri A, Trabelsi A, Steele AD (2009) Rotavirus infection and intussusception in Tunisian children: implications for use of attenuated rotavirus vaccines. J Pediatr Surg 44: 2133-2138.

30. Chen YE, Beasley S, Grimwood K, and the New Zealand Rotavirus Study Group (2005) Intussusception and rotavirus associated hospitalization in New Zealand. Arch Dis Child 90: 1077-1081.
31. Santos N and Hoshino Y (2005) Global distribution of rotavirus serotypes/genotypes and its implication for the development and implementation of an effective rotavirus vaccine. Rev Med Virol 15: 29-56.

32. Jain V, Das BK, Bhan MK, Glass RI, Gentsch JR and the Indian Strain Surveillance Collaborating Laboratories (2001) Great Diversity of Group A Rotavirus Strains and High Prevalence of Mixed Rotavirus Infections in India. J Clin Microbiol 39: 3524-3529.

33. Barril PA, Martinez LC, Giordano MO, Castello AA, Rota RP, Isa MB, Masachessi G, Ferreyra LJ, Glikmann G, Nates SV (2006) Detection of Group A Human Rotavirus G9 genotype circulating in Còrdoba, Argentina, as early as 1980. J Med Virol 78: 1113-1118.

34. Fischer TK, Eugen-Olsen J, Pedersen AG, Mølbak K, Böttinger B, Rostgaard K, Nielsen NM (2005) Characterization of Rotavirus strains in a Danish population: high frequency of mixed infections and diversity within the VP4 gene of P[8] strains. J Clin Microbiol 43: 1099-1104.

35. Nielsen NM, Eugen-Olsen J, Aaby P, Mølbak K, Rodrigues A, Fischer TK (2005) Characterization of Rotavirus strains among hospitalized and non-hospitalized children in Guinea-Bissau, 2002. A high frequency of mixed infections with serotype G8. J Clin Microbiol 34: 13-121.

\section{Corresponding author}

Christabel C Enweronu-Laryea MRCPCH, FGCP

Department of Child Health

University of Ghana Medical School

P O Box 4236

Accra, Ghana

Telephone: +233208154886

Email: chikalaryea@gmail.com

Conflict of interests: No conflict of interests is declared. 